\title{
Access to Evolution
}

\author{
Lara Eldredge
}

Published online: 27 March 2009

(C) Springer Science + Business Media, LLC 2009

With magnifying glasses in hand, twelve girls and boys from East Side Community High School's sixth grade awaited the arrival of their guides at the American Museum of Natural History. They were here not to revisit the renowned old dinosaur halls or to peruse the latest temporary exhibition but to make a study of the museum building itself. Indeed, this would be a unique school trip to the museum, for their guides were none other than paleontologist Dr. Niles Eldredge and geologist Sidney Horenstein, experts in evolution and in the study of the fossil record. These students were about to delve into the basics of evolutionary theory by discovering that evidence of previous life forms is not confined to inaccessible laboratories or distant excavation sites. In fact, such evidence resides conspicuously in the stones of the very buildings that surround us in our daily urban lives.

Despite the absence of evolution in New York City's sixth grade curriculum, the students' science teacher, Maria Agurcia, felt that it was imperative to introduce these ideas to her students at a young age. She explains, "There are so many misconceptions around the word 'theory.' Most young students come into middle school believing that the 'theory' of evolution is just an idea, a hypothesis, and that it hasn't really been accepted by all scientists." Maria's interest in teaching evolution dates back to her time at Duke University when she was working towards her Masters of Arts in Teaching. She chose evolution as the topic for her required graduation unit, and she included her

Electronic supplementary material Supplementary material is available in the online version of this article at 10.1007/s12052-009$0120-9$ and is accessible for authorized users.

\section{Eldredge $(\triangle)$}

East Side Community High School,

Manhattan, NY, USA

e-mail: larasan@gmail.com lesson plans in her online teaching portfolio (www.duke. edu/ mja8). However, this was the first time that Maria would have the opportunity to teach this subject to middle school students.

Since time constraints made it impossible to develop an extended evolution unit in her curriculum, Maria realized that the few activities that she could provide for her sixth graders would have to make a lasting impression. Hoping that the experience would be both educational and memorable, her unit culminated with an opportunity for several of her students to visit with "actual scientists." In order to assure that the fieldtrip provided the greatest value, Maria prepared her students in advance. She introduced them to several lesson plans from Fossil Factory, an activity book that Dr. Eldredge co-wrote with his two sons, Douglas and Gregory, when they were not much older than Maria's students.

Maria found the lessons in Fossil Factory to be "very accessible for the sixth grade age group." She used the book for her lesson on geologic time, and when she taught them about fossil formation, her students made casts and molds by following the book's procedures. When her students were required to read directly from Fossil Factory, Maria found, "The text was kid-friendly and very much at their reading level. They read about ancient trilobites, how fossils form, and how the earth has changed over time (Pangaea, plate tectonics, continental drift)." Co-written by children, Fossil Factory proved adept at balancing ageappropriate instruction with fun activities and visual representations. Maria explained that, since she had previously only taught evolution at the high school level, "having a book geared towards younger kids made it easier to understand how to address their needs and abilities."

While Maria was still in the planning phase of her evolution mini-unit, Dr. Eldredge learned that she was going to use Fossil Factory in her classroom. He was enthusiastic 
that the book he co-wrote with his own children would be utilized in this manner and soon offered to invite several of Maria's students to join him for a tour of the American Museum of Natural History. Since their host is known for his work in establishing the theory of Punctuated Equilibria and as an expert on Charles Darwin, this was unquestionably a special offer for the students to receive.

Dr. Eldredge also invited his colleague, Sidney Horenstein, to meet with the students. As one of the foremost geologists versed in fossils native to regional rock beds, Mr. Horenstein's expertise would complement the tour by demonstrating to the children that it is not necessary to travel to the distant countryside in order to discover fossils. Both Dr. Eldredge and Mr. Horenstein wanted the students to walk away from the experience with an understanding that fossils can be readily found in unexpected and easily accessible places. To this end, the two scientists mapped a path through the interior of the museum and out onto neighboring streets to observe the fossils embedded in the stones of nearby residential buildings.

On the day of the fieldtrip, the scientists introduced themselves simply as Niles and Sid and maintained a familiar tone with the students throughout the course of the tour. Their first point of interest was, surprisingly enough, an interior staircase off the main entrance to the museum. Bewilderment spread from face to face as the students attempted to guess why, in a museum filled with intricate dioramas and interactive displays, they had stalled on something so mundane as the floor. "Who can find the prehistoric clam in this stone?" Sid asked, and it dawned on the students that it was their turn to become detectives and to sleuth out the hidden fossils. Magnifying glasses flew up to eyes and soon Kevon was congratulated for making the first discovery of the day.

The students were likewise enthralled by the stories that Niles told about some of his own adventures in fossil collecting. Gathered around a display case of excavation tools, Niles explained how he would extract specimens from the ground during the day and then bring them back to his hotel room to pack them for safekeeping in the evening. The students were tickled to discover that oftentimes something as familiar as toilet paper would be used to protect the precious smaller fossils until they could be brought back to the lab for further examination.

Maria was impressed by how well her students responded to their fieldtrip. Most of them had visited the museum in previous years, but she believes that this experience had a more enduring impact on them. After the fieldtrip, Maria reflected, "The kids will always remember this trip more than other trips to the museum because our guides were real scientists. It made a huge difference." In teaching evolution, and other similarly complex subjects, students need to be provided with memorable activities so the information will continue to resonate with them in the long term. Likewise, it is important to recognize the role that access plays in cultivating an environment where students identify themselves as empowered and successful. The value of having access to respected scientists with whom to share in a meaningful discourse is immeasurable.

The students' school, East Side Community High School, is located on the Lower East Side of Manhattan and serves a population of students who struggle daily with many of the issues that prevent inner city children from pursuing a higher education. It is rare that New York City Public School students get the opportunity to witness the exhilaration of discovery that scientists display when studying and explaining the natural world. On the day of this fieldtrip, the enthusiasm was palpable from both the scientists and the students. For many of the students, meeting real-life scientists brought them one step closer to envisioning themselves as future scientists. In any event, regardless of future career goals, a greater appreciation of the natural world can only serve to enrich children's lives.


